Article

\title{
An Intelligent Approach for Contact Pressure Optimization of PEM Fuel Cell Gas Diffusion Layers
}

\author{
Yongbo Qiu ${ }^{1}$, Peng Wu ${ }^{1}$, Tianwei Miao ${ }^{1}$, Jinqiao Liang ${ }^{1}$, Kui Jiao ${ }^{1}$, Tao Li ${ }^{2}$, Jiewei Lin ${ }^{1, *}$ and \\ Junhong Zhang ${ }^{1,3, *}$ \\ 1 State Key Laboratory of Engines, Tianjin University, Tianjin 300350, China; 2018201325@tju.edu.cn (Y.Q.); \\ 2019201135@tju.edu.cn (P.W.); 2018201321@tju.edu.cn (T.M.); darren_liangjq@tju.edu.cn (J.L.); \\ kjiao@tju.edu.cn (K.J.) \\ 2 Shanxi Heavy Duty Automobile Co., Ltd., Xi'an 710200, China; litao_ld@sxqc.com \\ 3 Renai College, Tianjin University, Tianjin 301636, China \\ * Correspondence: linjiewei@tju.edu.cn (J.L.); zhangjh@tju.edu.cn (J.Z.)
}

Received: 4 May 2020; Accepted: 16 June 2020; Published: 18 June 2020

Abstract: The compression of the gas diffusion layer (GDL) greatly affects the electrochemical performance of proton exchange membrane fuel cells (PEMFCs) by means of both the equivalent value and distribution of contact pressure, which depends on the packing manner of the fuel cell. This work develops an intelligent approach for improving the uniformity and equivalent magnitude of contact pressure on GDLs through optimizing the clamping forces and positions on end plates. A finite element (FE) model of a full-size single fuel cell is developed and correlated against a direct measurement of pressure between the GDL and a bipolar plate. Datasets generated by FE simulations based on the optimal Latin hypercube design are used as a driving force for the training of a radial basis function neural network, so-called the agent model. Once the agent model is validated, iterations for optimization of contact pressure on GDLs are carried out without using the complicated physical model anymore. Optimal design of clamping force and position combination is achieved in terms of better contact pressure, with the designed equivalent magnitude and more uniform distribution. Results indicate the proposed agent-based intelligent optimization approach is available for the packing design of fuel cells, stacks in particular, with significantly higher efficiency.

Keywords: PEMFC; clamping; GDL; contact pressure; artificial intelligent; agent model

\section{Introduction}

Proton exchange membrane fuel cells (PEMFCs) are considered a clean and portable power source, which is already being applied to cars, buses, and heavy trucks. The packing is very important for either stacks or a single cell to keep layers together and avoid over deformation. Proper packing design can ensure that fuel cell performances are not limited by structural mechanics [1-4].

Contact pressure on the gas diffusion layer (GDL) can affect the electrochemical performance of a fuel cell through contact resistance and porosity. Lee [5] investigated the effect of clamping torque on the polarization curve of fuel cells with different GDLs experimentally. It was found that the influence of the clamping torque on voltage and power density of the fuel cell depends on the GDL materials. Ge [6] also obtained similar conclusions that the compression ratio of GDLs indeed affects the fuel cell performance, i.e., the polarization curve and current density at different operating conditions. Chang [7] measured the contact resistance between GDLs and bipolar plates (BPPs) under various contact pressures. It was found that the effect of contact pressure on the fuel cell performance also correlates to the magnitude of the contact pressure. At a lower range of contact pressure, the increasing contact pressure can adequately reduce the contact resistance between layers so as to enhance the 
electrochemical performance. For a higher range of contact pressure, the increase in the contact pressure decreases the mass transport from gas channels to the catalyst layer, which has an adverse effect on the current density, despite that the ohmic resistance is decreased at the same time. It is also found that the contact pressure of GDLs can improve the thermal and electrical conductivities by decreasing contact resistance [8,9]. Leakage is another problem we must consider in the clamping design of fuel cells. Sometimes it is the pressure on the gasket that prevents the leakage, which may conflict with the contact pressure on the GDL. However, in most cases, low pressure on the gasket can be used as a constraint in the clamping design. References [10-12] also suggest that there should be an optimal clamping force for the fuel cell to reach better performance and avoid leakage at the same time.

A proper magnitude of clamping force or torque can result in a proper magnitude of nominal contact pressure on the GDL, which leads to a good nominal electrochemical performance of fuel cells. Apart from that, the pressure distribution on the GDL also affects the mass transport in channels and the contact resistance at the ribs. Peng [13] proved that nonuniformly distributed contact pressure has a great impact on current density distribution and adjusting the clamping can achieve a uniform distribution of the current density. Increasing the stiffness of the end plate (EP) can improve the pressure distribution on GDLs by means of increasing the thickness or using stiffer materials [14,15]. Hydraulic aided EPs [16,17] and composite EPs [18] were also proposed to get a better clamping pressure distribution.

A compromise between contact resistance, porosity, and leakage pressure should be achieved by optimizing the clamping of the fuel cell. In addition, an evenly distributed contact pressure on the GDL is preferable and benefits fuel cell performance. The traditional physical model-based optimization process is precise but time-consuming. It would be unimaginable that a large design of experiments or long iterations of optimization can be done by a 3D full-size fuel cell model in computational fluid dynamics (CFD) or finite element (FE) analysis. An agent model, which can fit the physical model well, would be useful and powerful for prediction and optimization [19-21]. While an agent model is developed and validated, the design of experiments can be done on a large scale, as well as the following optimization iterations, using artificial intelligence-based algorithms [22-27].

In this paper, an intelligent approach for predicting and optimizing the contact pressure on GDLs under various clamping designs is proposed. A full-size 3D FE model of a PEMFC for packing simulation is developed and validated. Then, a radial basis function neural network (RBFNN)-based agent model is trained and tested, according to the data generated by the FE simulation. Finally, aimed at obtaining an optimal contact pressure of the GDL, with a designed magnitude and uniform distribution, a genetic algorithm (GA) companied by the agent model is employed to carry out an optimization of the clamping design of PEMFCs.

\section{Methods}

\subsection{Algorithms}

\subsubsection{Optimal Latin Hypercube Design}

The optimal Latin hypercube design (Opt LHD) is used to generate design points from a great amount of sample space and to represent the relationship clearly between the design variables and the response [28]. The Opt LHD first selects several active pairs, which make the objective function value minimum. It finds the best components from the selected active pairs for minimizing the integrated mean squared error and maximizing the entropy. It selects pairs randomly and iterates until there is no further improvement. The constrained quasi-Newton routine algorithm is adopted to optimize the midpoint LHD. It searches for the optimal location in the interval by varying the coordinate from 0 to 1 . 


\subsubsection{RBFNN}

RBFNN [29] is a feed-forward neural network consisting of input, hidden, and output layers (shown in Figure 1). Input variables are sent to the nodes in the hidden layer with nonlinear transfer functions and then mapped to the output nodes. The output is given by a linear weighted summation of the hidden node responses at each node in the output layer. The Gaussian function is the most commonly used RBF in the hidden layer.

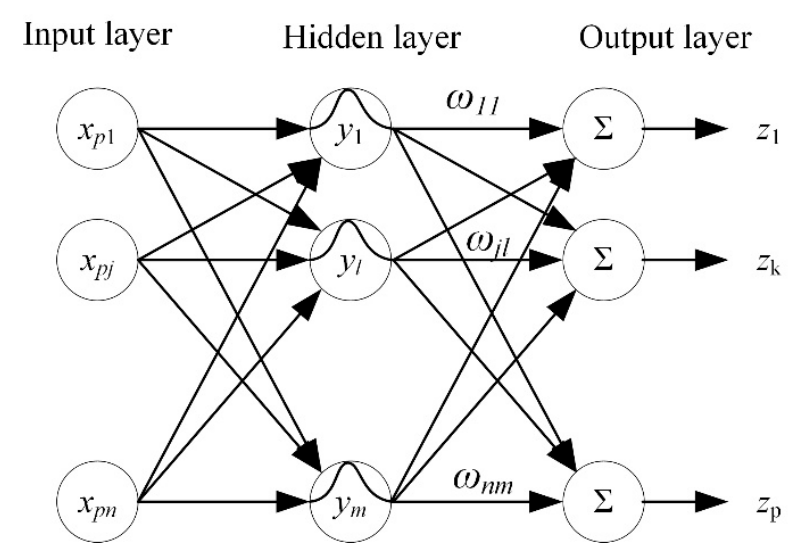

Figure 1. Structure of a radial basis function neural network (RBFNN).

\subsubsection{GA}

In GA, as shown in Figure 2, a searching point is an individual that initializes as the first population evolution starts. The fitness of the population is evaluated in every generation, and a number of individuals are stochastically selected according to the fitness and modified to form the next new population for the next iteration. The Genetic Algorithm Optimisation Toolbox implemented in MATLAB is used, and more details can be found in [30].

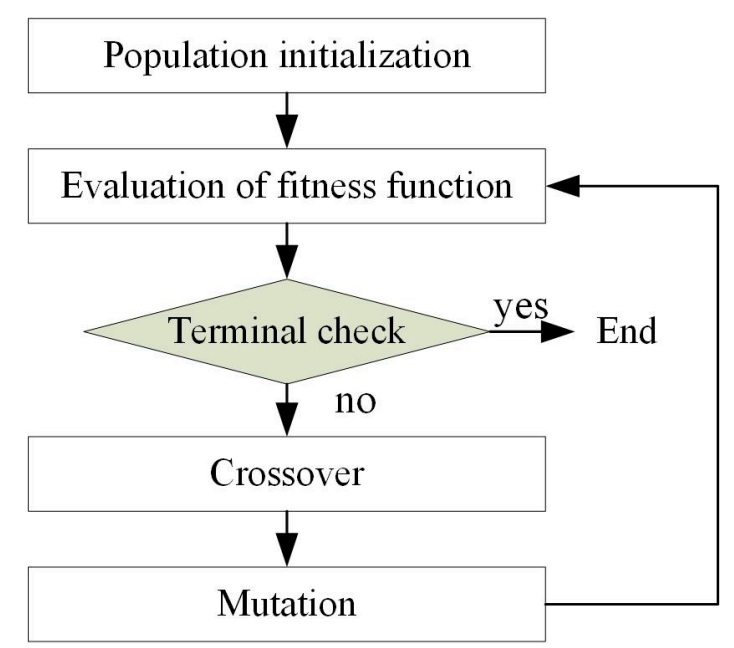

Figure 2. Workflow of the genetic algorithm.

\subsection{Objective and Workflow}

An evenly distributed contact pressure on the GDL is the optimization objective in this work to achieve a better balance between the contact resistance and the porosity by ensuring a safe pressure on the gasket to prevent leakage. The scheme of the proposed approach is described in Figure 3. 


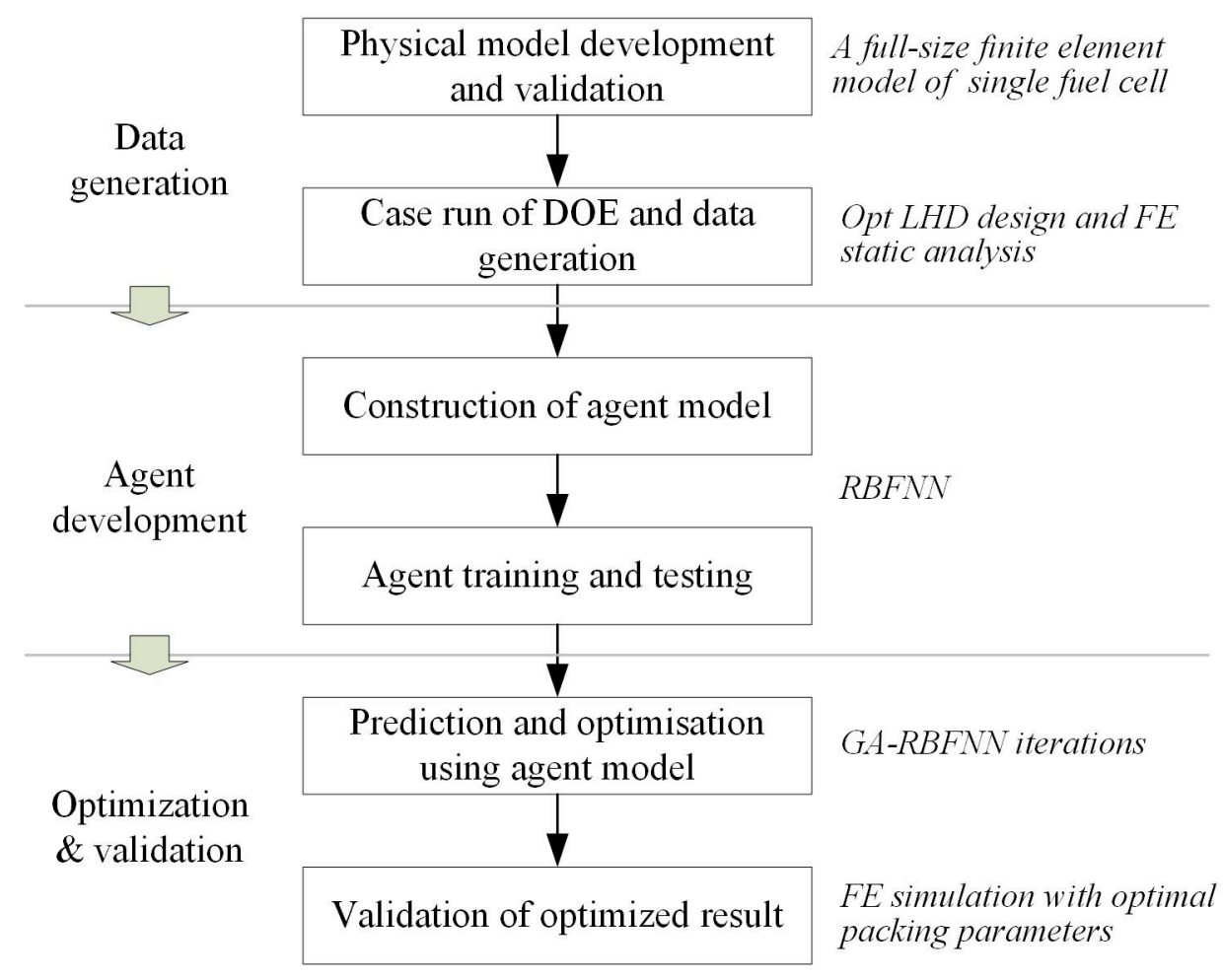

Figure 3. Framework of the intelligence-based prediction and optimization approach.

Step 1. Data generation

Develop a full-size 3D FE model of a single fuel cell to give predictions of the contact pressure between the GDL and the BPP under various clamping conditions to generate a database.

Step 2. Agent model development

Construct, train, and verify an RBFNN that can precisely reproduce the desired results to replace the physical model with much higher computational efficiency.

Step 3. Optimization and validation

Optimize the contact pressure based on the verified agent model by GA to obtain the best combination of design variables of clamping. Run the physical model with the optimal setup as validation.

\section{Physical Model}

\subsection{Geometry}

A FE model of a single fuel cell (as shown in Figure 4) was developed in ABAQUS based on the following assumptions: (1) The single fuel cell is symmetric according to the middle planes in all the three translational directions, so $1 / 8$ section of the full model can represent the mechanical performance of the whole fuel cell; (2) round corners at the end of the parallel channels on BPP are considered as straight corners since they have little effect on the distribution and mean value of the contact pressure on the GDL; (3) catalyst layers are integrated on the PEM due to its very thin thickness and the negligible effect of mechanical properties on the deformation of the GDL. The FE model consists of EPs, insulation plates, collectors, gaskets, BPPs, GDLs, and PEM. 


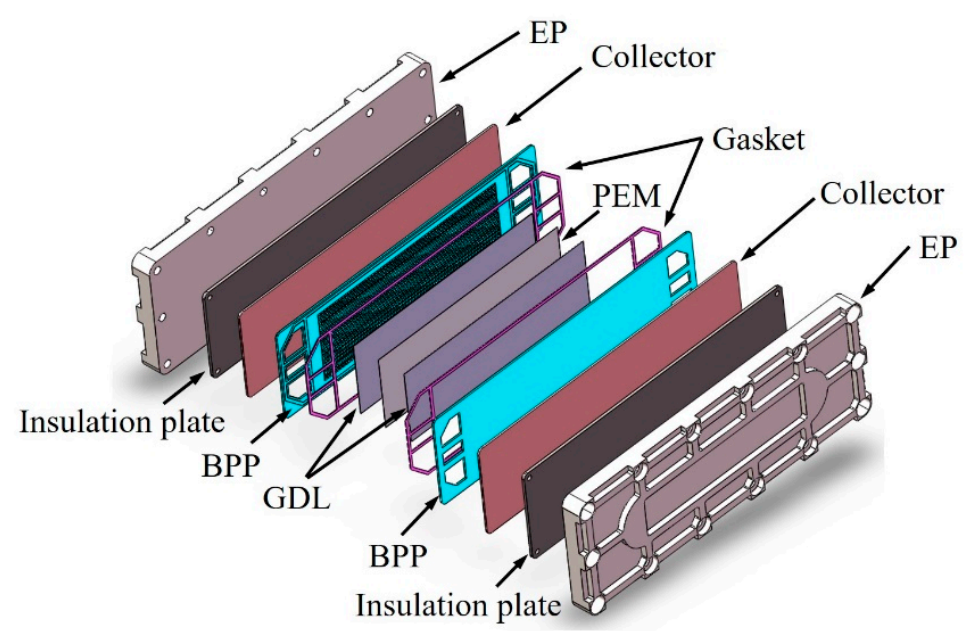

Figure 4. Full-size model of a proton exchange membrane fuel cell (PEMFC).

\subsection{Meshing}

Meshes of size from 0.1-2.0 mm were employed to fit the geometry variety between substructures. In total, 326,282 elements were finally used for the 1/8 fuel cell model. C3D8R hexahedron elements with 8 nodes were used, and the locally refined grids at the interfaces of BPP, GDL, and PEM are shown in Figure 5.

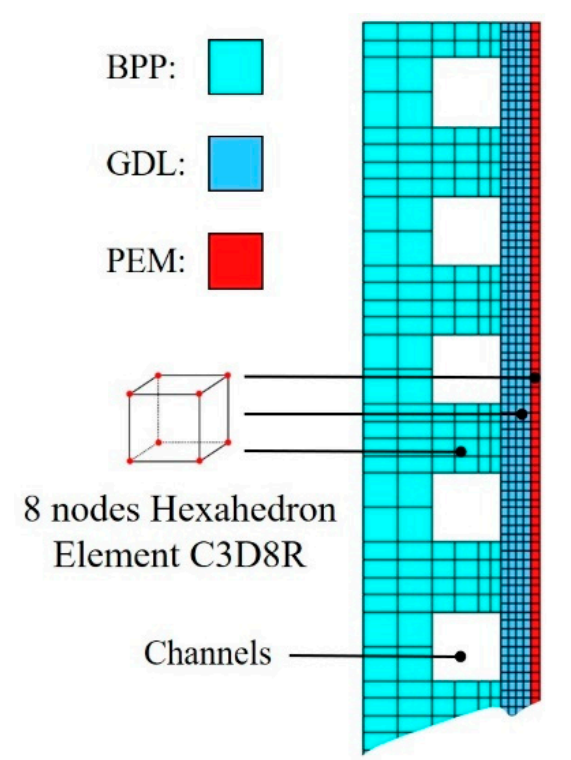

Figure 5. Locally refined meshes of the fuel cell model.

\subsection{Boundary and Loading Conditions}

GDLs and PEM were tied together to simulate the hot-pressing process. Other interfaces between substructures are defined as contact with a tangential friction coefficient of 0.2. The clamping forces were applied to the nut area. Symmetry constraints were used on the longitudinal and lateral planes, and fixed constraints were given to the middle plane of the PEM, as shown in Figure 6. 


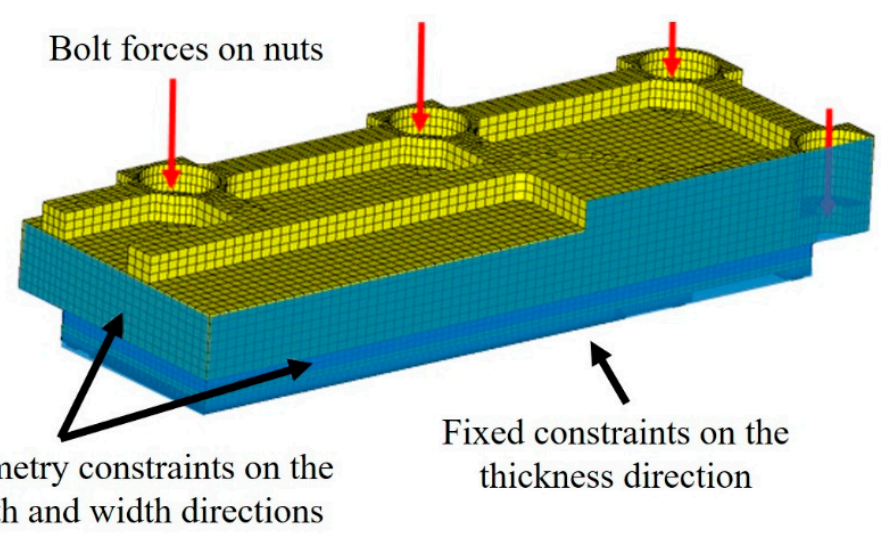

Figure 6. Boundary and loading conditions of the finite element (FE) model.

\subsection{Material Properties}

Material properties of the GDL and the PEM were obtained from suppliers; that of the EP, the collector, and the BPP were obtained from [31]; that of the insulation plate and the gasket were obtained from [32]. Details are listed in Table 1.

Table 1. Material properties used in the FE model.

\begin{tabular}{cccc}
\hline Component & Material & Young's Modulus (GPa) & Poisson's Ratio \\
\hline EP [31] & Steel & 200 & 0.3 \\
Insulation plate [32] & Epoxylite & 1 & 0.38 \\
Collector [31] & Copper & 110 & 0.34 \\
Gasket [32] & PTFE & 0.28 & 0.4 \\
BPP [31] & Graphite & 10 & 0.25 \\
GDL & - & 0.01 & 0.25 \\
PEM & - & 0.249 & 0.25 \\
\hline
\end{tabular}

\section{Results and Discussion}

\subsection{FE Model Validation}

Pressure-sensitive films ( $200 \mu \mathrm{m}$, Fuji LLW) were used to detect the contact pressure between BPP and the GDL after a single fuel cell is packed with bolts. The effective range of the sensitive film is $0.5-2.5 \mathrm{MPa}$. After 5-min of standing still, the sensitive film was taken out, showing a contour of contact pressure on the GDL.

Static analysis of the FE model under exactly the same clamping force was carried out to calculate the contact pressure on the GDL of the same fuel cell, and the result is given in Figure 7. From the measurement, it was found the pressure distributes quite uniformly on the GDL surface; solid contacts can be found at the four corners and along the width edges. The contact pressure of the central area along the longitudinal direction was very low. The contact pressure inside the black dashed line was even lower than $0.6 \mathrm{MPa}$ - a very poor contact between the BPP ribs and the GDL, which may result in high contact resistance. The longitudinal edges also showed a relatively low level of contact pressure, which is unexpected since these two edges are close to the clamping bolts. There may be two reasons: (1) The tightening sequence of bolts is the four corners first and then the middle ones, so the capsules at the corners broke first and led to a deep color at the contour, but the contact in the middle area was not as good as the corners despite that the same clamping forces are given; (2) the machining tolerance of EP, BPP, and the gasket may also have prevented the GDL from contacting the ribs of BPP. 


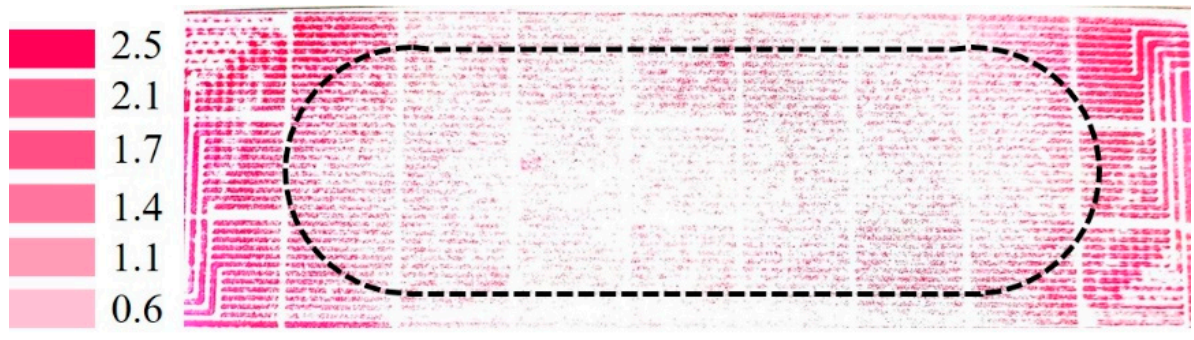

(a)

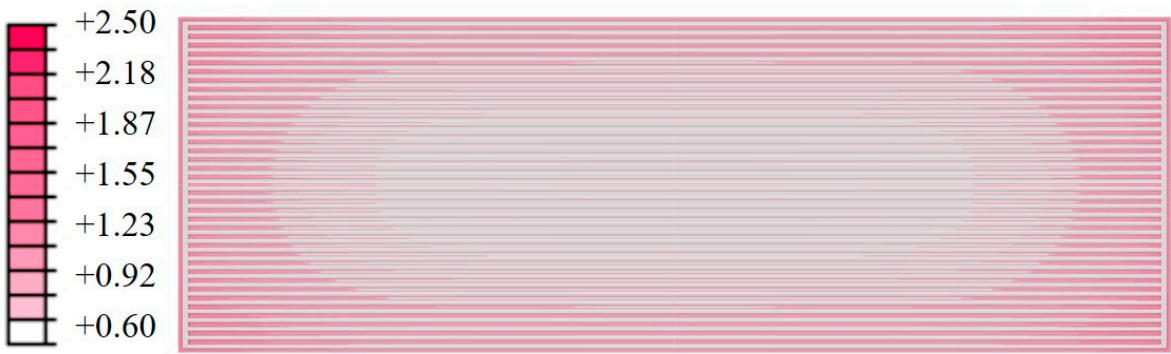

(b)

Figure 7. Comparison of contact pressure between (a) experiment and (b) FE simulation.

Overall speaking, the FE simulation shows the same distribution pattern of the contact pressure on the GDL surface. The pressure gradually decreases from outside to the center, and the very central area shows a pressure lower than 0.6 MPa. From the comparison, very similar distributions can be seen between the experimental and calculated contact pressures in both magnitude and trend. That is to say, the FE model developed is able to reflect the mechanical performance of the GDL after packing.

\subsection{Distribution of Contact Pressure}

The contact pressure contour of the GDL can be broken down into two directions, as shown in Figure 8. Figure $8 \mathrm{a}$ shows the contact pressure under a rib along the channel direction. The GDL under a rib is compressed tightly at the inlet and outlet and loosely in the middle, which shows a basin curve, with around $0.3 \mathrm{MPa}$ difference between the peak and the valley. At the ends close to bolts, a maximum $0.75 \mathrm{MPa}$ contact pressure means the GDL is compressed a lot and loses porosity. With increasing distance away from the bolts, the contact pressure drops sharply and then goes stable at around $0.48 \mathrm{MPa}$ at the bottom. In this case, the whole rib-GDL contact area shows two different patterns according to the contact pressure. The bottom area in the middle section, taking about $50 \%$ of the channel length, holds a stable contact pressure. The contact pressure of the outer sections near the end of the channel grows sharply and reaches the peak at the inlet and outlet.

In the cross-channel direction, as shown in Figure $8 \mathrm{~b}$, the contact pressure fluctuates in a "rib edge-rib center-channel" pattern. The sharp peaks represent the stress concentrations at the rib edges because the contact form changes from channel-GDL (non-contact) to rib-GDL (solid-contact). So, the zero-contact pressure means the GDL is not compressed at all under the channel. Valleys around 0.6 $\mathrm{MPa}$ between rib edges represent the most of the GDL under ribs, which shows a median compression. From the whole width point of view, the contact pressure still performs as a basin shape according to the distance from the edge.

Overall, the distribution of contact pressure on the GDL oscillates a lot, which is not preferable for maximizing fuel cell performance. The contact in the center needs to be enhanced, and that at the edge needs to be controlled. 


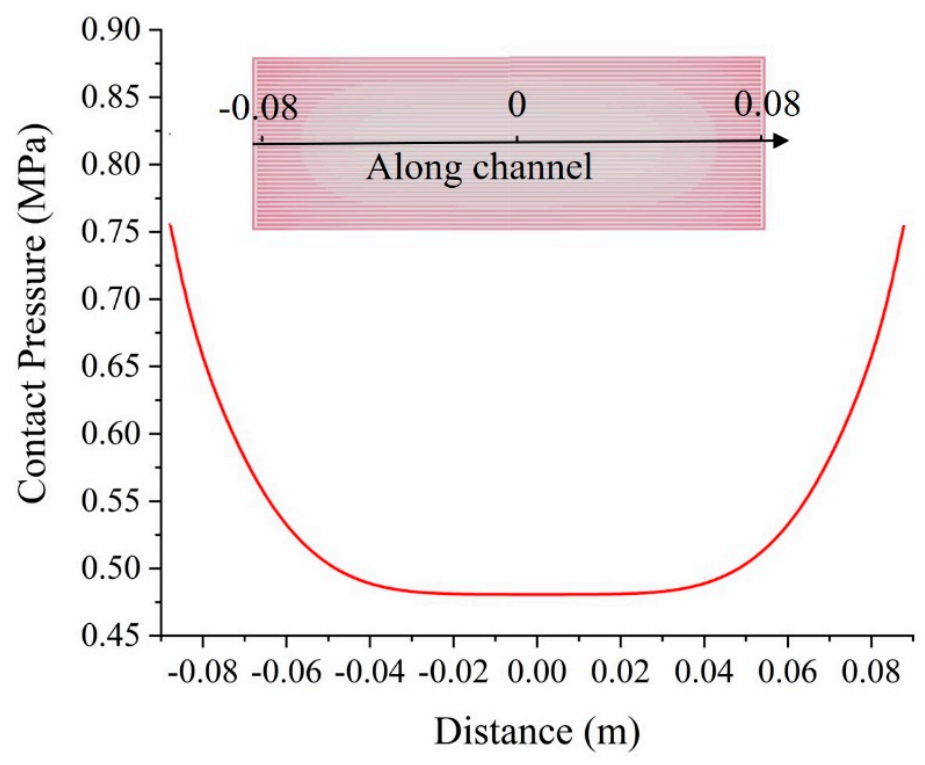

(a)

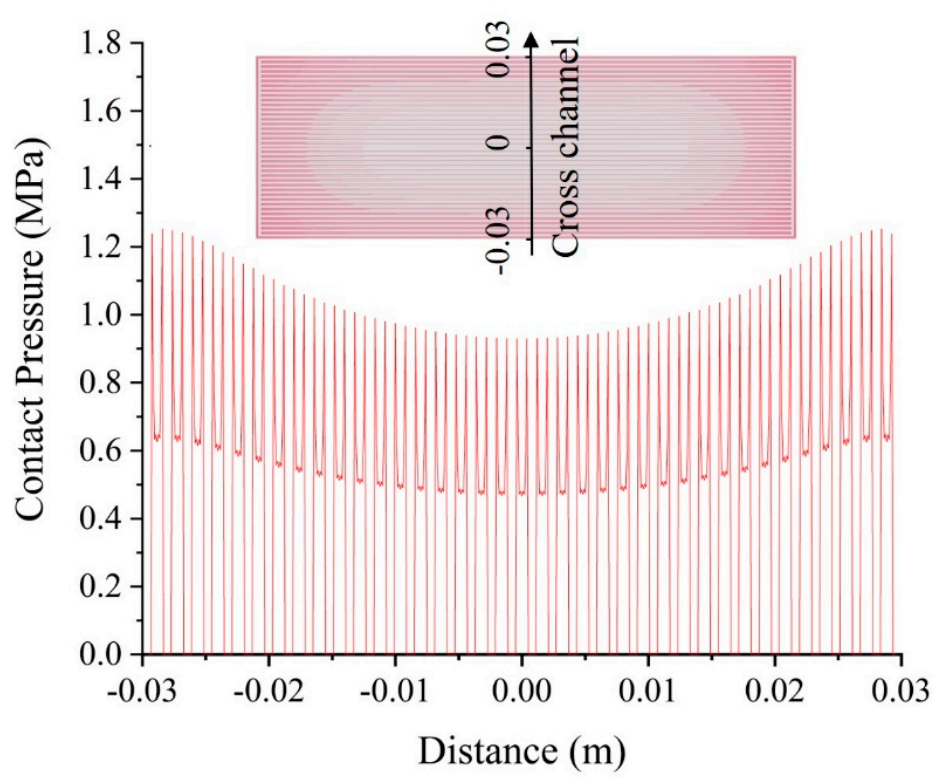

(b)

Figure 8. Contact pressure distributions (a) along the channel and (b) across the channel.

\subsection{Agent Model Performance}

Bolt position and clamping force play big roles in the contact pressure of the GDL, so these two factors are considered design variables. In Figure $9, L_{1}, L_{2}$, and $L_{3}$ are positions of the three bolts, and Bolt 4 is fixed because it is right on the symmetric plane, so a change in position of Bolt 4 will lead to an increase in bolt numbers that is not preferable. So, design variables are the positions of Bolts 1-3 and the clamping forces on Bolts 1-4. The position of the bolt can only slide along the edge to ensure the reaction area is not affected. As a result, an 80-run design space is generated using the Opt LHD method. 


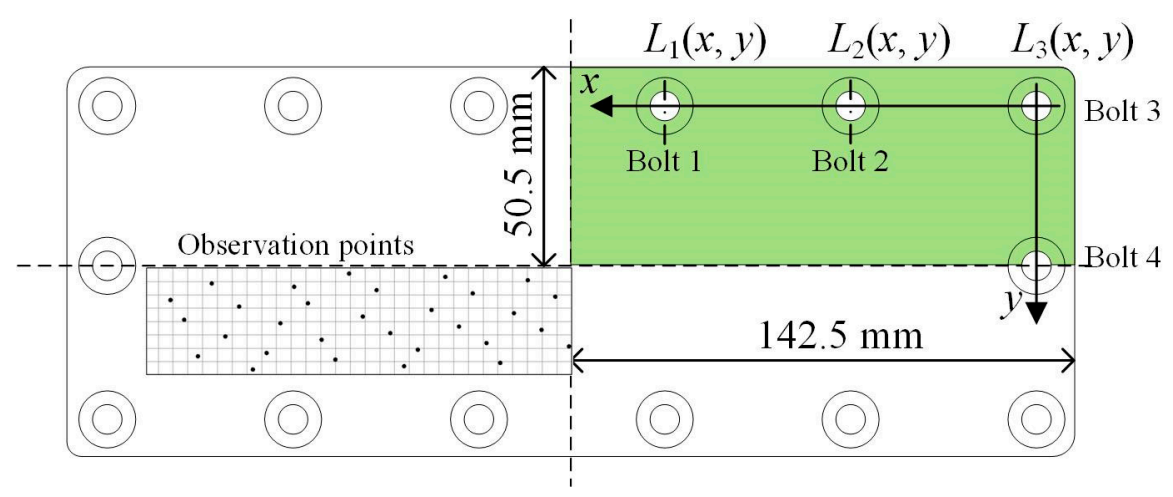

Figure 9. Schematic of the structure design of fuel cell packing.

Eighty simulations were run by the FE model, and corresponding contact pressure results of the GDL were obtained. Thirty observation points (see Figure 9) were picked averagely on the GDL, and the data space was conducted with the contact pressure on the GDL. Seventy-five out of eighty datasets were randomly picked as training data, and the remaining 5 groups (noted as R2, R6, R15, R62, R76) were taken as test data, as listed in Table 2. An RBFNN-based agent model was then trained and tested. Relative error (RE) is employed to assess the performance of the agent model. As shown in Figure 10, the average RE between predictions of the agent model and the FE results is $4.9 \%$. Figure 11 shows the error contour of contact pressure on the GDL obtained from the observation points. It can be seen that the REs of most areas are lower than $5 \%$, and the biggest gap between the prediction and the FE model is around 7.5\%. Nevertheless, the prediction accuracy of the RBFNN-based agent model is more than acceptable, considering the computational cost is significantly decreased.

Table 2. Train and test data sets generated by the optimal Latin hypercube design (Opt LHD).

\begin{tabular}{cccccccc}
\hline Run & $\boldsymbol{F}_{\mathbf{1}}$ & $\boldsymbol{F}_{\mathbf{2}}$ & $\boldsymbol{F}_{\mathbf{3}}$ & $\boldsymbol{F}_{\mathbf{4}}$ & $\boldsymbol{L}_{\mathbf{1}}$ & $\boldsymbol{L}_{\mathbf{2}}$ & $\boldsymbol{L}_{\mathbf{3}}$ \\
\hline R1 & 76.9 & 2076.9 & 1923.1 & 2769.2 & 101.2 & 68.9 & 16.5 \\
R2 & 1153.8 & 1769.2 & 76.9 & 1692.3 & 120.3 & 42.4 & 36 \\
R3 & 1692.3 & 1307.7 & 1230.8 & 2615.4 & 123.7 & 72.4 & -17 \\
$\ldots$ & $\ldots$ & $\ldots$ & $\ldots$ & $\ldots$ & $\ldots$ & $\ldots$ & $\ldots$ \\
R80 & 1307.7 & 615.4 & 2076.9 & 2461.5 & 92.1 & 52.8 & 35 \\
\hline
\end{tabular}

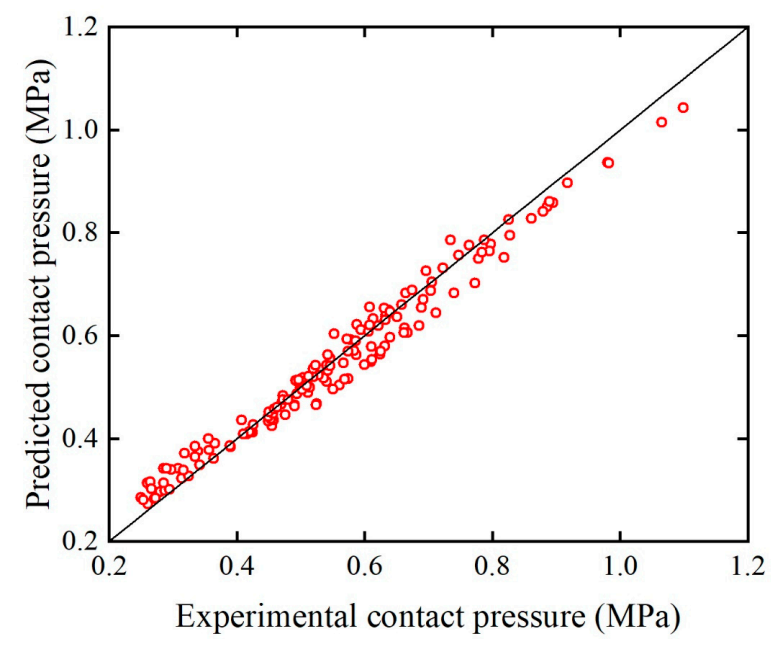

Figure 10. Predictions of the contact pressure of the agent model and the FE model. 


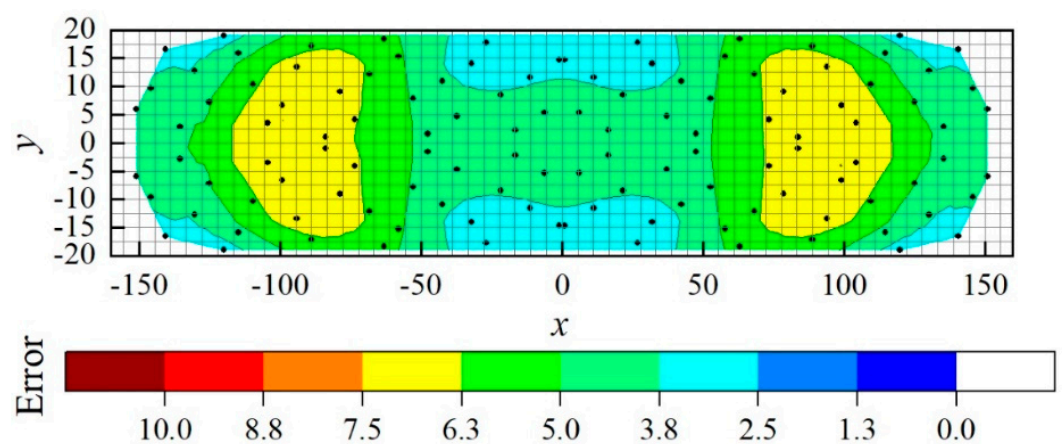

Figure 11. Error contour of contact pressure prediction on the gas diffusion layer (GDL).

\subsection{Optimization of Packing}

Compromise should be made between the contact resistance and the porosity by means of varying the clamping force on the fuel cell on the premise of no leakage. The optimal clamping force depends on the structure, the material of BPP, GDL, and MEA, as well as the target operating voltage. In this study, 0.5 MPa is set as the object contact pressure for SGL-10-BB GDL to achieve optimum current density under $0.5-0.6 \mathrm{~V}$ operating voltage [11]. The optimization problem is defined as

Find:

$$
X=\left(F_{1}, F_{2}, F_{3}, F_{4}, L_{1}, L_{2}, L_{3}\right)
$$

Minimize:

$$
P(X)=\frac{\sum_{i=1}^{30}\left|P_{i}(X)-0.5\right|}{30}
$$

Subject to

$$
\left\{\begin{array}{l}
0 \leq F_{1}, F_{2}, F_{3}, F_{4} \leq 3000 \mathrm{~N} \\
(91,0) \leq L_{1}(x, y) \leq(135,0) \mathrm{mm} \\
(32,0) \leq L_{2}(x, y) \leq(77,0) \mathrm{mm} \\
(8,0) \leq L_{3}(x, y) \leq(18,0) \mathrm{mm} \text { or }(0,8) \leq L_{3}(x, y) \leq(0,36) \mathrm{mm}
\end{array}\right.
$$

where $X$ is the set of design variables. Since the objective contact pressure on the GDL is set as $0.5 \mathrm{MPa}$, the corresponding pressure on the gasket, which is much stiffer than the GDL, should be high enough to avoid leakage so there is no need to consider the seal problem in this optimization, neither as a constraint nor as the lower limit of clamping force. The RBFNN-based agent model is used in the fitness function of GA. The population size is 40 , the probability of crossover is 0.7 , the probability of mutation is 0.01 , the maximum generation number is 100 , and the generation gap is 0.9 . The convergence process of optimization and final optimal results are given in Figure 12.

The optimum combination of design parameters obtained is $X=(2146.63,1750.73,325.51,2524.93$, 107.47, 44.62, 35.85), as shown in Figure 13 in red. It can be seen that the positions of Bolts 1 and 2 are moved towards the right side, and Bolt 3 is moved to the central line. The clamping force of Bolt 4 is the largest, followed by Bolt 1 and Bolt 2. The clamping force of Bolt 3 is far smaller. Additionally, the optimized position of Bolt 3 is very close to Bolt 4 . For the sake of engineering practice, Bolt 3 was removed from the packing, which can also lower the cost and lighten the weight of the fuel cell (in total, 4 bolts were removed for a full fuel cell).

The final optimum packing design was fed back to the FE model, and the corresponding contact pressure on GDL was calculated. For comparison, the clamping force of origin design was also adjusted to reach a comparable level of the mean contact pressure to the optimized design. The contours of contact pressure of the original and optimized packing designs are given in Figure 14. As we can see, the high contact pressure at the four corners is significantly reduced by $24 \%$ from 2.12 to $1.61 \mathrm{MPa}$ in the optimized case. At a similar mean contact pressure level, the maximum value decreases and the minimum value increases. The standard deviation of contact pressure decreases from 0.071 to 
$0.049 \mathrm{MPa}$ by $31 \%$. The apparent border between solid-contact and loose-contact areas is merged and the bad-contact area is eliminated. In other words, the uniformity of contact pressure on the GDL is greatly improved, with a well-designed equivalent pressure magnitude.

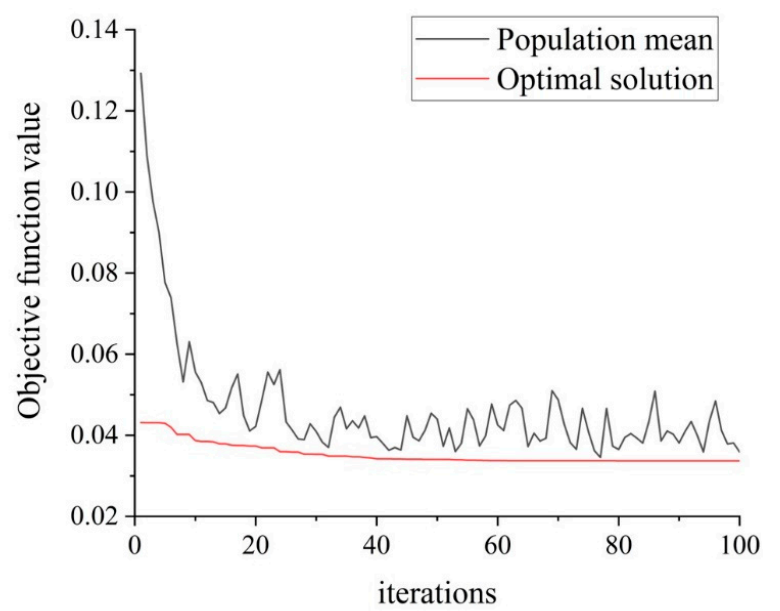

(a)

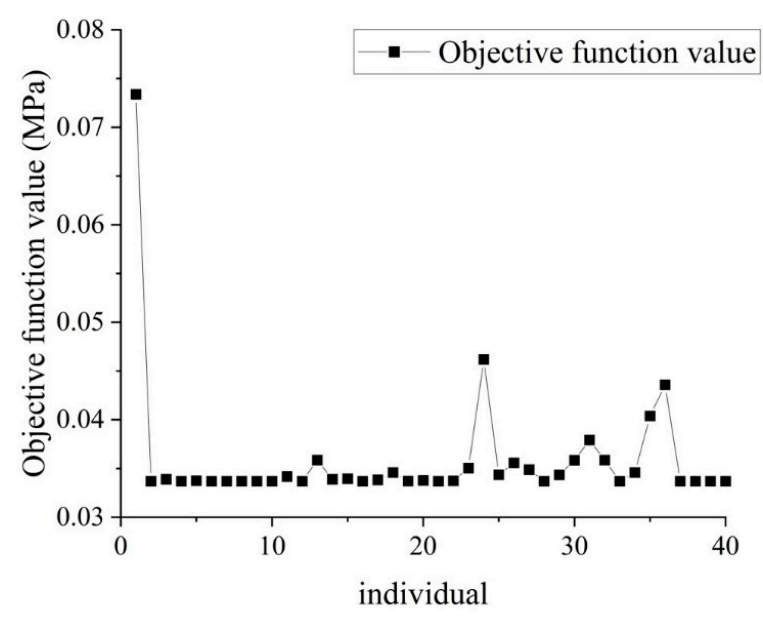

(b)

Figure 12. Objective function values of (a) iterations and (b) individuals.

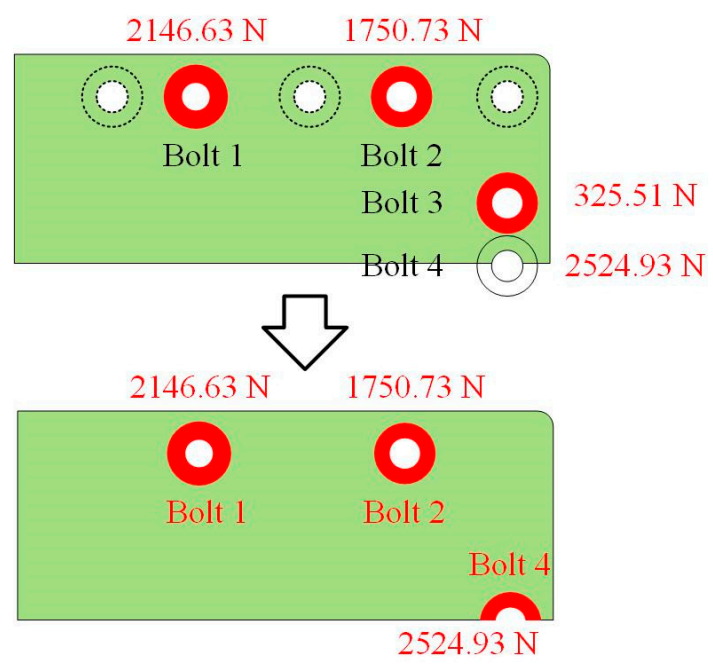

Figure 13. Optimal packing design with 2.5 -bolts in a $1 / 8$ fuel cell. 

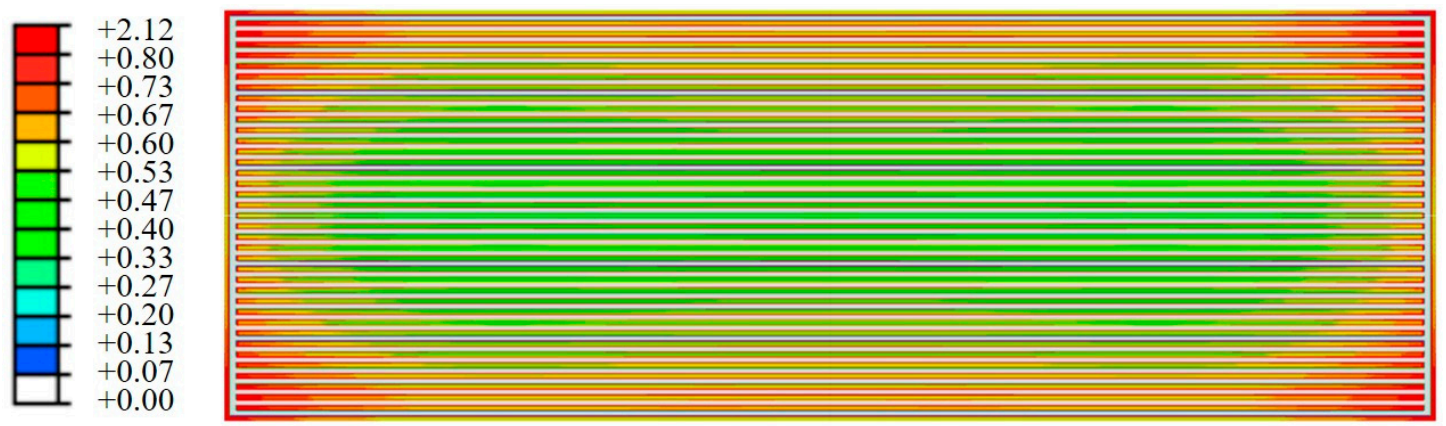

(a)
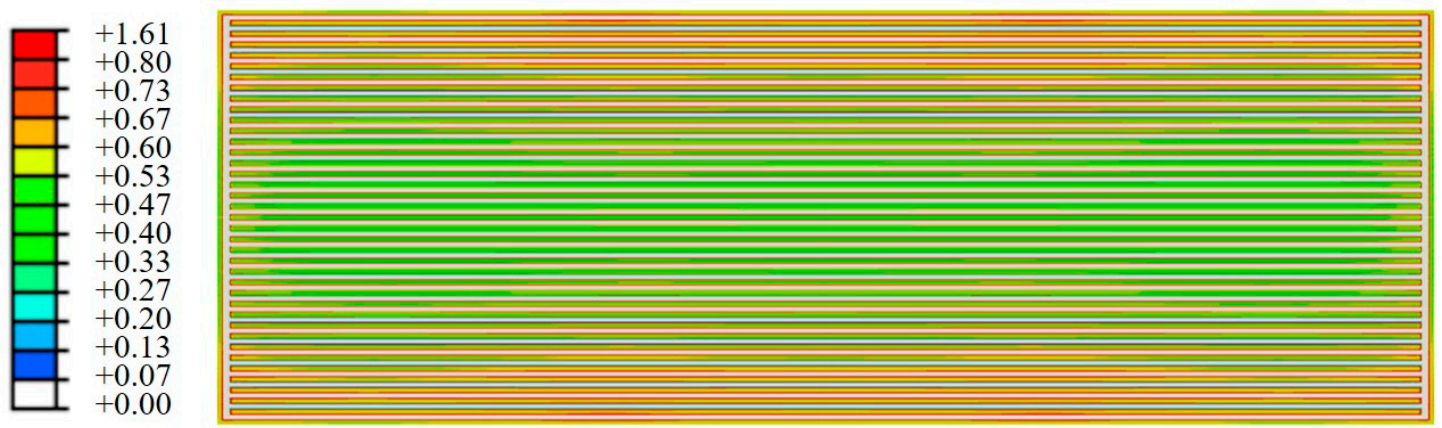

(b)

Figure 14. Comparison of contact pressure distributions of (a) original and (b) optimized designs.

\section{Conclusions}

This work presents an intelligence-based approach of clamping optimization for proper contact pressure on the GDL of a PEMFC. Opt LHD, RBFNN, and GA are employed to conduct the proposed intelligent workflow on the basis of a validated full-size physical model of the fuel cell. Conclusions can be drawn as follows:

The data-driven RBFNN-based agent model is capable of representing the inner physical phenomenon of a fuel cell, i.e., the contact pressure between BP and the GDL under various clamping conditions. It provides a possibility of getting higher computational efficiency in the mechanical prediction of fuel cells.

A uniform distribution of the contact pressure on the GDL with a properly designed equivalent value can be obtained through adjusting the clamping manner, even for a traditional bolt packing case.

The RBFNN-GA-based optimization framework is available for multi-objective optimization of the complex structure with much lower computing cost, which has great potential for clamping designs for fuel cell stacks.

Author Contributions: Conceptualization, Y.Q., K.J., and J.L. (Jiewei Lin); data curation, Y.Q. and P.W.; methodology, Y.Q.; project administration, J.L. (Jiewei Lin) and T.L.; resources, J.L. (Jiewei Lin) and J.Z.; supervision, J.L. (Jiewei Lin); validation, T.M. and J.L. (Jinqiao Liang); writing—original draft, Y.Q.; writing-review and editing, J.L. (Jiewei Lin). All authors have read and agreed to the published version of the manuscript.

Acknowledgments: The authors gratefully acknowledge the National Key R\&D Program of China (Fuel Cell Engine Integration and Control for Heavy Duty Trucks-Vehicle Integration of Fuel Cell Heavy Duty Trucks) and the Natural Science Foundation of Tianjin (China) (18JCYBJC20000).

Conflicts of Interest: The authors declare that they have no known competing financial interests or personal relationships that could have appeared to influence the work reported in this paper. 


\section{References}

1. Movahedi, M.; Ramiar, A.; Ranjber, A.A. 3D numerical investigation of clamping pressure effect on the performance of proton exchange membrane fuel cell with interdigitated flow field. Energy 2018, 142, 617-632. [CrossRef]

2. Xu, Y.; Qiu, D.; Yi, P.; Lan, S.; Peng, L. An integrated model of the water transport in nonuniform compressed gas diffusion layers for PEMFC. Int. J. Hydrogen Energy 2019, 44, 13777-13785. [CrossRef]

3. Li, L.; Wang, S.; Wang, G.; Yue, L.; Takuto, A. Effect of clamping stress on Cold Start Performance of PEMFC. Energy Procedia 2019, 158, 1744-1749. [CrossRef]

4. Zhou, Y.; Jiao, K.; Du, Q.; Yin, Y. Gas diffusion layer deformation and its effect on the transport characteristics and performance of proton exchange membrane fuel cell. Int. J. Hydrogen Energy 2013, 38, 12891-12903. [CrossRef]

5. Lee, W.; Ho, C.; Van Zee, J.W.; Murthy, M. The effects of compression and gas diffusion layers on the performance of a PEM fuel cell. J. Power Sources 1999, 84, 45-51. [CrossRef]

6. Ge, J.; Higier, A.; Liu, H. Effect of gas diffusion layer compression on PEM fuel cell performance. J. Power Sources 2006, 159, 922-927. [CrossRef]

7. Chang, W.R.; Hwang, J.J.; Weng, F.B.; Chan, S.H. Effect of clamping pressure on the performance of a PEM fuel cell. J. Power Sources 2007, 166, 149-154. [CrossRef]

8. Bazylak, A.; Sinton, D.; Liu, Z.S.; Djilali, N. Effect of compression on liquid water transport and microstructure of PEMFC gas diffusion layers. J. Power Sources 2007, 163, 784-792. [CrossRef]

9. Cha, D.; Ahn, J.H.; Kim, H.S.; Kim, Y. Effects of clamping force on the water transport and performance of a PEM (proton electrolyte membrane) fuel cell with relative humidity and current density. Energy 2015, 93, 1338-1344. [CrossRef]

10. Qiu, D.; Yi, P.; Peng, L.; Lai, X. Assembly design of proton exchange membrane fuel cell stack with stamped metallic bipolar plates. Int. J. Hydrogen Energy 2015, 40, 11559-11568. [CrossRef]

11. Zhou, P.; Wu, C.W.; Ma, G.J. Influence of clamping force on the performance of PEMFCs. J. Power Sources 2007, 163, 874-881. [CrossRef]

12. Xing, X.Q.; Lum, K.W.; Poh, H.J.; Wu, Y.L. Optimization of assembly clamping pressure on performance of proton-exchange membrane fuel cells. J. Power Sources 2010, 195, 62-68. [CrossRef]

13. Peng, L.; Shao, H.; Qiu, D.; Yi, P.; Lai, X. Investigation of the non-uniform distribution of current density in commercial-size proton exchange membrane fuel cells. J. Power Sources 2020, 453, 227836. [CrossRef]

14. Asghari, S.; Shahsamandi, M.H.; Ashraf Khorasani, M.R. Design and manufacturing of end plates of a $5 \mathrm{~kW}$ PEM fuel cell. Int. J. Hydrogen Energy 2010, 35, 9291-9297. [CrossRef]

15. Alizadeh, E.; Barzegari, M.M.; Momenifar, M.; Ghadimi, M.; Saadat, S.H.M. Investigation of contact pressure distribution over the active area of PEM fuel cell stack. Int. J. Hydrogen Energy 2016, 41, 3062-3071. [CrossRef]

16. Alizadeh, E.; Ghadimi, M.; Barzegari, M.M.; Momenifar, M.; Saadat, S.H.M. Development of contact pressure distribution of PEM fuel cell's MEA using novel clamping mechanism. Int. J. Hydrogen Energy 2017, 131, 92-97. [CrossRef]

17. Wang, X.; Song, Y.; Zhang, B. Experimental study on clamping pressure distribution in PEM fuel cells. J. Power Sources 2008, 179, 305-309. [CrossRef]

18. Yu, H.N.; Kim, S.S.; Suh, J.D.; Lee, D.G. Composite endplates with pre-curvature for PEMFC (polymer electrolyte membrane fuel cell. Compos. Struct. 2010, 92, 1498-1503. [CrossRef]

19. Wang, B.; Zhang, G.; Wang, H.; Xuan, J.; Jiao, K. Multi-physics-resolved digital twin of proton exchange membrane fuel cells with a data-driven surrogate model. Energy AI 2020, 1, 100004. [CrossRef]

20. Wang, B.; Xie, B.; Xuan, J.; Jiao, K. AI-based optimization of PEM fuel cell catalyst layers for maximum power density via data-driven surrogate modeling. Energy Convers. Manag. 2020, 205, 112460. [CrossRef]

21. Zhang, J.; Wang, J.; Lin, J.; Guo, Q.; Chen, K.; Ma, L. Multiobjective optimization of injection molding process parameters based on Opt LHD, EBFNN, and MOPSO. Int. J. Adv. Manuf. Technol. 2016, 85, 2857-2872. [CrossRef]

22. Bejan, A. AI and freedom for evolution in energy science. Energy AI 2020, 100001. Available online: https:// www.researchgate.net/publication/340097977_AI_and_Freedom_for_Evolution_in_Energy_Science (accessed on 18 June 2020).

23. Jin, D.; Ocone, R.; Jiao, K.; Xuan, J. Energy and AI. Energy AI 2020, 100002. Available online: https: //researchportal.hw.ac.uk/en/publications/energy-and-ai (accessed on 18 June 2020). 
24. Krzywanski, J.; Fan, H.; Feng, Y.; Shaikh, A.R.; Fang, M.; Wang, Q. Genetic algorithms and neural networks in optimization of sorbent enhanced H2 production in FB and CFB gasifiers. Energy Convers. Manag. 2018, 171, 1651-1661. [CrossRef]

25. Yan, Z.; He, A.; Hara, S.; Shikazono, N. Modeling of solid oxide fuel cell (SOFC) electrodes from fabrication to operation: Microstructure optimization via artificial neural networks and multi-objective genetic algorithms. Energy Convers. Manag. 2019, 198, 111916. [CrossRef]

26. Zhao, J.; Ma, Y.; Zhang, Z.; Wang, S.; Wang, S. Optimization and matching for range-extenders of electric vehicles with artificial neural network and genetic algorithm. Energy Convers. Manag. 2019, 184, 709-725. [CrossRef]

27. Krzywanski, J.; Grabowska, K.; Herman, F.; Pyrka, P.; Sosnowski, M.; Prauzner, T.; Nowak, W. Optimization of a three-bed adsorption chiller by genetic algorithms and neural networks. Energy Convers. Manag. 2017, 153, 313-322. [CrossRef]

28. Zhang, J.; Guo, P.; Lin, J.; Wang, K. A mathematical model for coupled vibration system of road vehicle and coupling effect analysis. Appl. Math. Model. 2016, 40, 1199-1217. [CrossRef]

29. Fernando, D.A.K.; Jayawardena, A.W. Runoff forecasting using RBF networks with OLS algorithm. J. Hydrol. Eng. 1998, 3, 203-209. [CrossRef]

30. Houck, C.; Joines, J.; Kay, M. A Genetic Algorithm for Function Optimization: A MATLAB Implementation; NCSUIE-TR-95-09; North Carolina State University: Raleigh, NC, USA, 1998; Volume 22.

31. Chien, C.; Hu, Y.; Su, T.; Liu, H.; Wang, C.; Yang, P.; Lu, Y. Effects of bolt pre-loading variations on performance of GDL in a bolted PEMFC by 3-D FEM analysis. Energy 2016, 113, 1174-1187. [CrossRef]

32. Yan, M.; Liu, B.; Li, J. China Aeronautical Materials Handbook, 2nd ed.; China Standards Press: Beijing, China, 2002; Chapter 7; ISBN 7-5066-2665-9.

(C) 2020 by the authors. Licensee MDPI, Basel, Switzerland. This article is an open access article distributed under the terms and conditions of the Creative Commons Attribution (CC BY) license (http://creativecommons.org/licenses/by/4.0/). 